\title{
AN ASYMPTOMATIC LIPOLEIOMYOMA IN POST MENOPAUSAL WOMAN: A CASE REPORT
}

Mahendra Singh ${ }^{1}$, Moushmi Mukherjee², Jagjeewan Ram³ ${ }^{3}$ Chayanika Pantola ${ }^{4}$, S. Iram Arshad ${ }^{5}$

\section{HOW TO CITE THIS ARTICLE:}

Mahendra Singh, Moushmi Mukherjee, Jagjeewan Ram, Chayanika Pantola, S. Iram Arshad. "An Asymptomatic Lipoleiomyoma in Post-Menopausal Woman: A Case Report". Journal of Evolution of Medical and Dental Sciences 2015; Vol. 4, Issue 47, June 11; Page: 8234-8238, DOI: 10.14260/jemds/2015/1193

\begin{abstract}
Lipoleiomyoma is a rare benign neoplasm. Most cases of lipoleiomyoma cannot be distinguished clinically from leiomyoma and can be diagnosed typically by gross glistening yellow appearance of tumour. The majority patients do not report any symptoms. Almost all cases of lipoleiomyoma reported in postmenopausal women are predominantly located in the uterus; however, extrauterine locations have also been reported. We report a case of intramural lipoleiomyoma in posterolateral uterine wall in 60 years old postmenopausal female who presented with mild cystocele.
\end{abstract}

KEYWORDS: Lipoleiomyoma, Menopause, Uterus.

INTRODUCTION: Lipoleiomyoma is a rare neoplasm consisting of smooth muscle and mature adipocytes. Reported incidence varies from $0.03 \%$ to $0.2 \% .^{[1]}$ Most patients are perimenopausal and postmenopausal predominantly in fifties and sixties.[2]

Lipoleiomyoma are associated with ordinary leiomyoma. Contrary to uterine myomas which are usually found in women at reproductive age and regress after menopause. The signs and symptoms are similar to those caused by ordinary leiomyoma. Most patients are asymptomatic.[3] $0 n$ USG leiomyoma appears as hyperechoic mass partially encased by a hypoechoic rim. The rim is thought to represent a layer of myometrium surrounding the fatty component.[1]

CASE REPORT: A 65 years old postmenopausal woman with gravida 4 para 3 presented with complaints of mild cystocele associated with burning micturition and abdominal lump gradually increasing in size since 9 months. She has attained menopause at age of 50 years.

On vaginal examination, the uterus was anteverted and bilateral fornices were free and nontender. Her complete blood count, blood sugar profile, hepatic and renal function were within normal limits. Her chest x-ray PA view, electrocardiogram revealed no abnormality. Her ultrasonography of the abdomen and pelvis revealed a hyperechoic with partially hypoechoic rim arising from the uterus measuring $4.6 \times 4.1 \mathrm{~cm}$ with high fat content with posterior acoustic attenuation and poor vascularity. Total abdominal hysterectomy with bilateral salpingo-oopherectomy was done and sent for histopathology.

Grossly on cutting open through the uterine cavity a well circumscribed yellowish fibroid measuring $4 \times 4 \mathrm{~cm}$ was present in the posterolateral uterine wall. on cut section of fibroid, glistening yellow areas seen and another greyish white area of whorling was also identified measuring $1 \times 1 \mathrm{~cm}$. cervix and both adnexa were normal and unremarkable. Microscopically tumour was composed of adipose tissue admixed with connective tissue septa. The tumour is not encapsulated but adjacent myometrium is compressed to form false capsule. Immunohistochemically smooth muscle fibres intervening the adipose tissue were positive for desmin and smooth muscle actin. Thus confirming the diagnosis of lipoleiomyoma. Post-operative follow up was uneventful. 
DISCUSSION: Pathologically lipomatous tumour of uterus have been categorized into 3 distinct group-: First group composed of mainly pure lipoma formed of encapsulated mature fat cells, second group of lipoma with mesodermal component such as lipoleiomyoma, angiomyolipoma, fibromyolipoma and rarest category of malignant neoplasm like liposarcoma which consist poorly differentiated fat cells undergoing sarcomatous change.[4,5]

Lipoleiomyoma is usually well circumscribed with a false capsule. These can be single or multiple, usually measuring $5-10 \mathrm{~cm}$ and size ranging from few $\mathrm{mm}$ to $32 \mathrm{~cm} .{ }^{[4,6]}$ Patients are mostly asymptomatic but can experience pelvic discomfort and pressure and vaginal bleeding.[6,7] Differential diagnosis of fat containing mass in female pelvis are benign cystic ovarian teratoma, ovarian lipoma, or possibly ovarian lipoleiomyoma.[5,8] Cases of liposarcoma developing from lipoleiomyoma have been reported. Another entity on the theme is adenolipoleiomyoma. We could also differentiate lipoleiomyoma from leiomyoma with fatty degeneration as adipose is distributed evenly throughout lesion and secondly lipomatous degeneration rarely occurs in smooth muscle tumour.

In addition lipoleiomyoma can be differentiated from leiomyosarcoma by bland nuclei and paucity of mitosis in smooth muscle component.[6,9] The origin of the lipomatous tumour is controversial and different theories have been proposed: 1. Misplaced embryonal mesodermal rest with a potential of lipoblastic differentiation, 2. Lipoblast or pluripotential cells migrating along uterine arteries and nerves, 3. Adipose metaplasia of stromal or smooth muscle cells in leiomyoma.[7] It was previously called fatty metamorphosis, lipomatous degeneration, adipose metaplasia.[10,11] It is now regarded as true neoplasm. This tumour has excellent prognosis.

\section{REFERENCES:}

1. A. Prieto, C. Crespo, A. Pardo, I. Docal, J. Calzada, P. Alonso, Uterine lipoleiomyomas: US and CT findings, Abdom Imaging, 25, 2000, 655-657.

2. L.M. Kauser, C.H. Carrasco, C.R. Sheehan, et al, Lipomatous tumour of the uterus; Radiographic and ultrasonic appearance, Br J Radiol, 52, 1979, 992-993.

3. D. A. Oppenheimer, B. A. Carroll, S.W. Young, Lipoleiomyoma of uterus, J Comput Assist Tomogr, 6, 1982, 640-642.

4. Kitajima K, Kaji Y, Imanaka K, Sugihara R, Sugimura K. MRI findings of uterine lipoleiomyoma correlated with pathologic fi ndings. AJR Am J Roentgenol 2007; 189: W100-4.

5. Warty TR, Chaudhari SN, Bal H, Ashtekar AA, Karan S. An Incidental, Asymptomatic Lipoleiomyoma in a Post- Menopausal Woman: A Case Report. Int J Sci Stud 2014; 2 (8): 258260.

6. Kumar S, Garg S, Rana P, Hasija S, Kataria SP, et al. (2013) Lipoleiomyoma of Uterus: Uncommon Incidental Finding. Gynecol Obstet 3: 145.doi: 10.4172/2161-0932.1000145.

7. Lau LU, Thoeni RF (2005) Uterine lipoma: Advantage of MRI over ultrasound.Br J Radiol 78: 72 74.

8. Dodd GD 3rd, Lancaster KT, Moulton JS. Ovarian lipoleiomyoma: A fat-containing mass in the female pelvis. AJR Am J Roentgenol 1989; 153: 1007-8.

9. Bajaj P, Kumar G, Agarwal K (2004) Lipoleiomyoma of broad ligament: A case report. Indian J Pathol Microbiol 3: 457-458.

10. Chan HHL, Chau MT, Lam CHL, Cheung SCW. Uterine lipoleiomyoma: ultrasound and computed tomography findings. J HK Coll Radiol. 2003; 6: 30-32. 


\section{CASE REPORT}

11. Loffroy R, Nezzal N, Mejean N, Sagot P, Krausé D. Lipoleiomyoma of the uterus: imaging features. Gynecol Obstet Invest. 2008; 66: 73-75. [PubMed] [DOI].

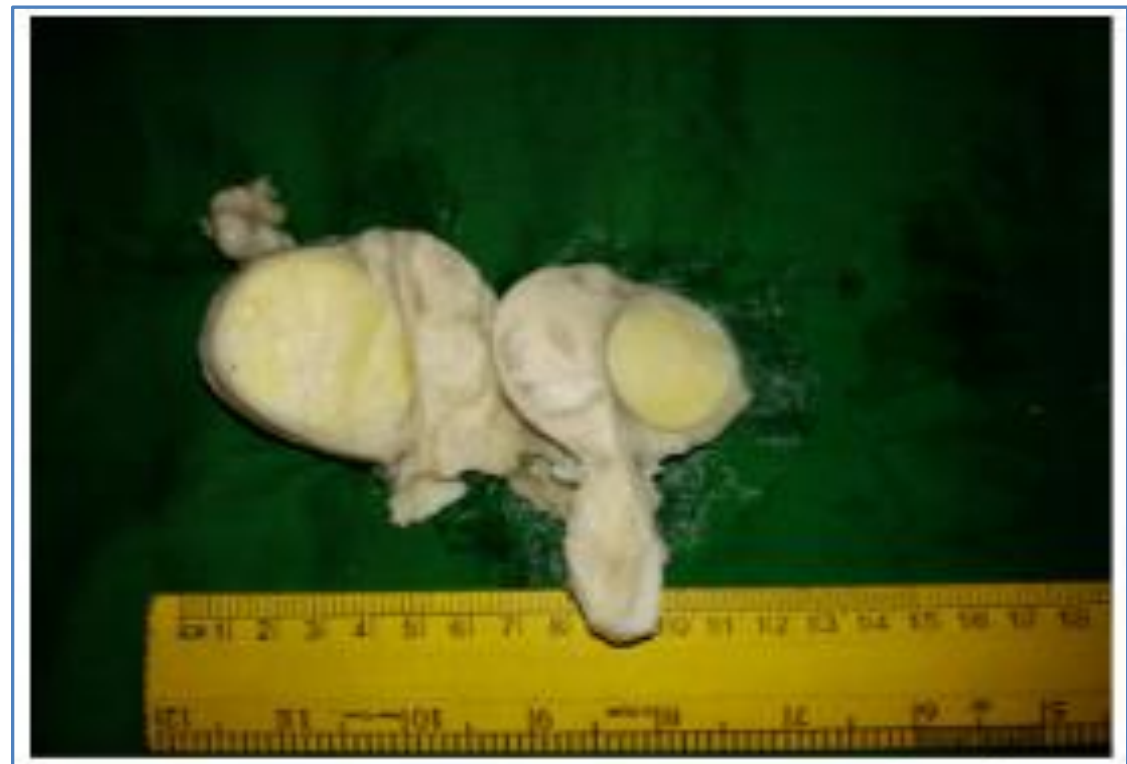

Fig. 1: On gross examination, a greyish yellow intramural fibroid mea $4 \times 4$ seen on one side

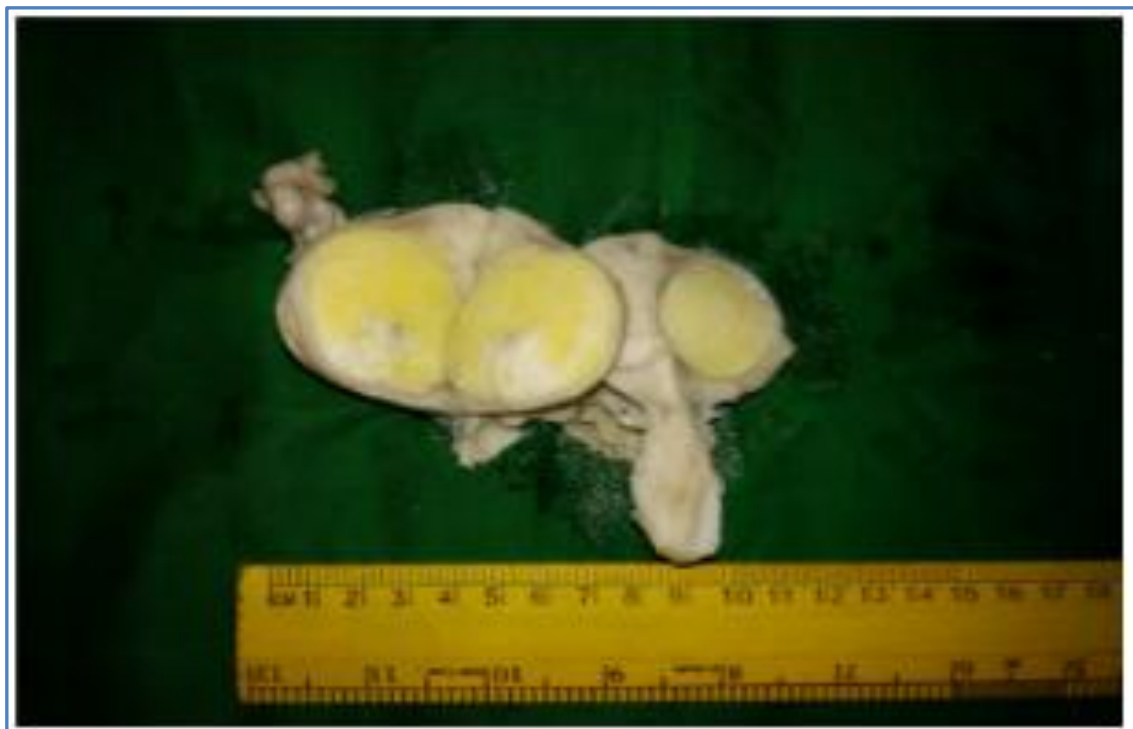

Fig. 2: On cut section, glistening yellow areas seen 


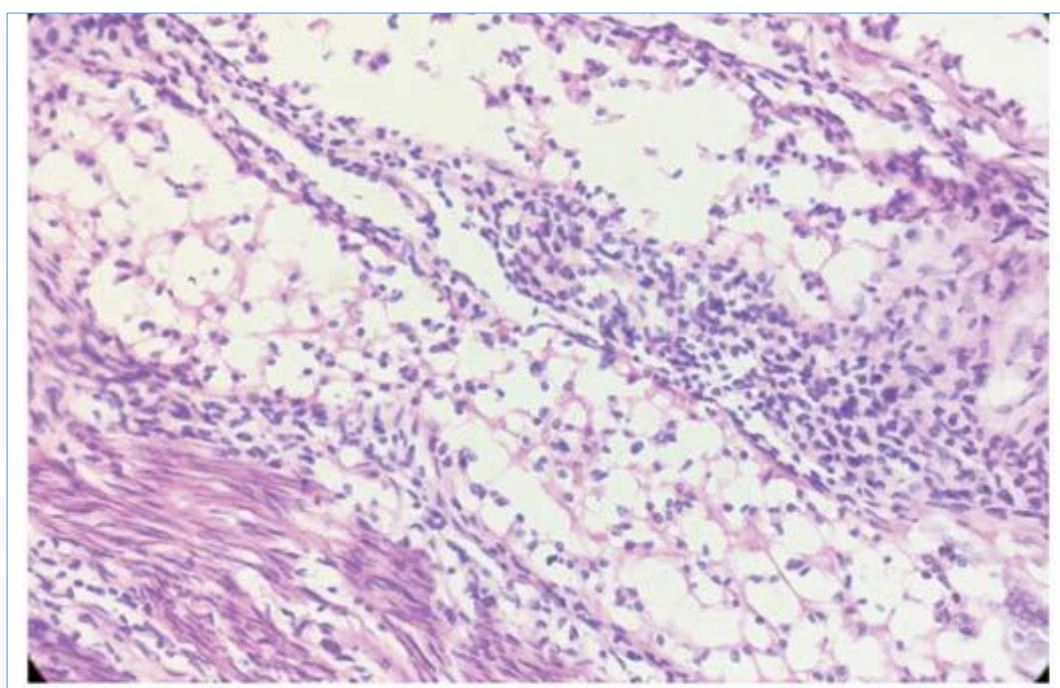

Fig-3 :- Well circumscribed proliferation of smooth muscle cells in a whorled pattern admixed with mature adipocyte ( $\mathrm{H} \& \mathrm{E}$ stain, $40 \mathrm{x})$

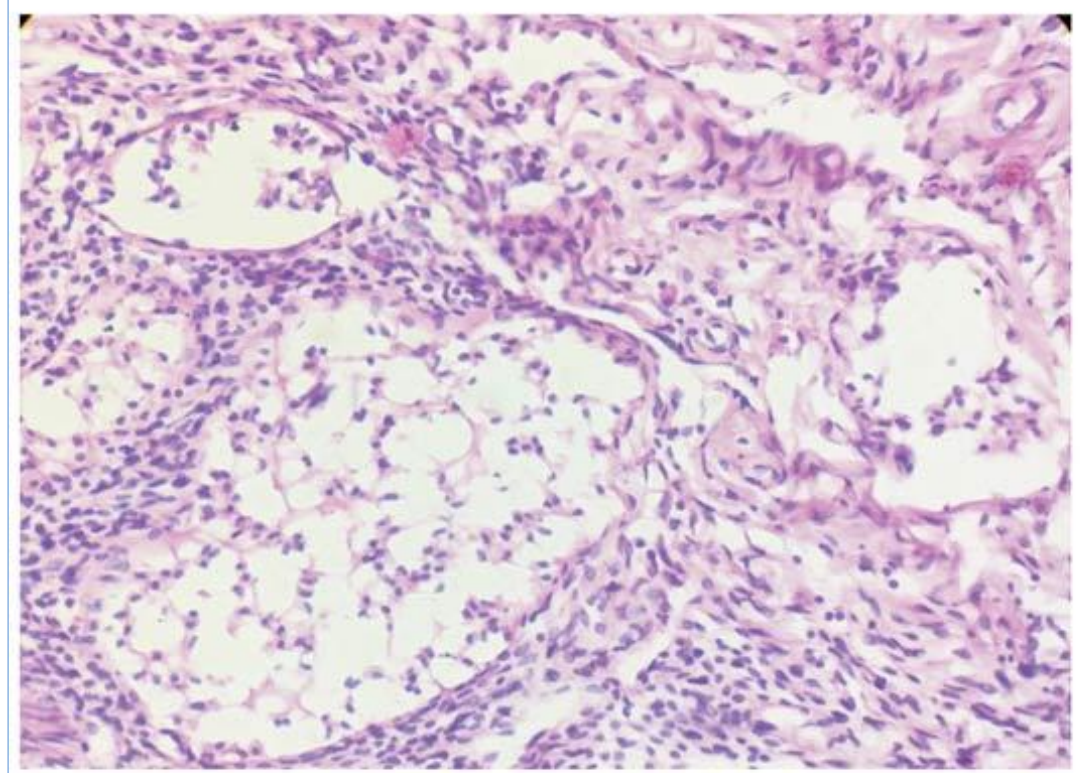

Fig-4 (H \& E stain, 40x) 


\section{CASE REPORT}

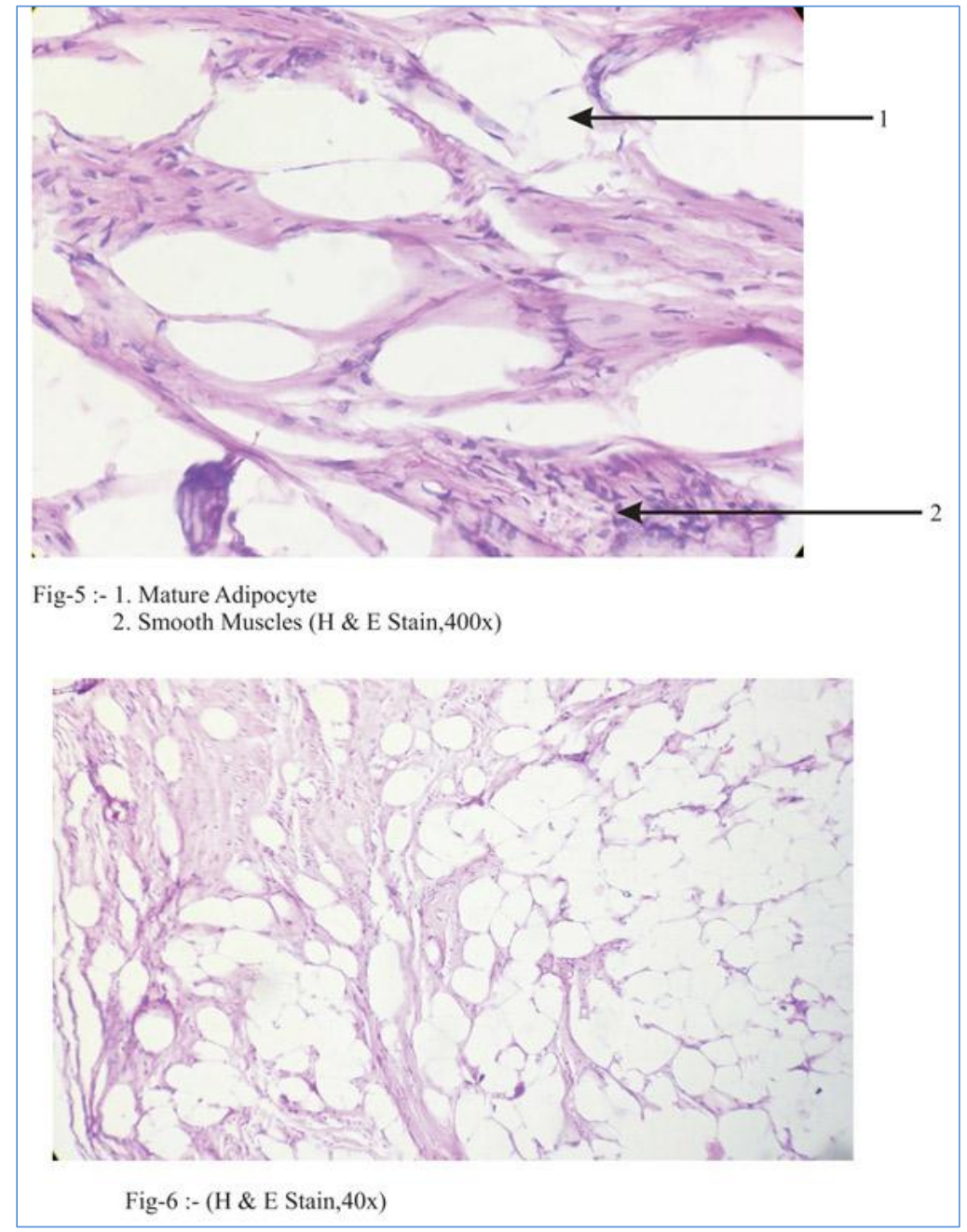

\section{AUTHORS:}

1. Mahendra Singh

2. Moushmi Mukherjee

3. Jagjeewan Ram

4. Chayanika Pantola

5. S. Iram Arshad

\section{PARTICULARS OF CONTRIBUTORS:}

1. Professor \& HOD, Department of Pathology, GSVM Medical College, Kanpur.

2. Junior Resident, Department of Pathology, GSVM Medical College, Kanpur.

3. Assistant Professor, Department of Pathology, GSVM Medical College, Kanpur.

\section{FINANCIAL OR OTHER} COMPETING INTERESTS: None
4. Assistant Professor, Department of Pathology, GSVM Medical College, Kanpur.

5. Junior Resident, Department of Pathology, GSVM Medical College, Kanpur.

\section{NAME ADDRESS EMAIL ID OF THE CORRESPONDING AUTHOR:}

Dr. Moushmi Mukherjee,

C-51, Bima Vihar, Lakhanpur, Kanpur, Uttar Pradesh.

E-mail: moushmimukherjee28@gmail.com

Date of Submission: 05/05/2015.

Date of Peer Review: 12/05/2015.

Date of Acceptance: 04/06/2015.

Date of Publishing: 11/06/2015. 